\title{
New approaches to improve the efficiency of somatic embryogenesis in oil palm (Elaeis guineensis Jacq.) from mature zygotic embryos
}

\author{
Talita Aparecida Balzon • Zanderluce Gomes Luis • \\ Jonny Everson Scherwinski-Pereira
}

Received: 3 January 2011 / Accepted: 31 October 2012 /Published online: 9 January 2013 / Editor: Brent Tisserat

(C) The Society for In Vitro Biology 2013

\begin{abstract}
We developed an efficient and simple system for inducing somatic embryogenesis and regenerating plantlets from mature zygotic embryos of oil palm. Embryogenic calli were induced from mature zygotic embryos of oil palm on modified Murashige and Skoog medium with 2,4-dichlorophenoxyacetic acid or picloram, alone or in combination with activated charcoal. The greatest frequency of embryogenic callus induction $(97.5 \%)$ was obtained by culturing mature zygotic embryos on callus induction medium with $450 \mu \mathrm{M}$ picloram and $2.5 \mathrm{gL}^{-1}$ activated charcoal. Embryogenic calli proliferated on a medium with a reduced concentration of picloram. Embryogenic calli were then subcultured on a medium supplemented with $12.3 \mu \mathrm{M}$ 2-isopentenyladenine and $0.54 \mu \mathrm{M}$ naphthaleneacetic acid, with subcultures at 4-wk intervals. Somatic embryos were regenerated on a medium with Murashige and Skoog macro- and micronutrients at halfstrength concentrations supplemented with $20 \mathrm{gL}^{-1}$ sucrose, $2.5 \mathrm{gL}^{-1}$ activated charcoal, and $2.5 \mathrm{gL}^{-1}$ Phytagel. Detailed histological analysis revealed that somatic embryogenesis followed an indirect pathway. Primary calli were observed after 4-6 wk of culture and progressed to embryogenic calli at $12 \mathrm{wk}$. Embryogenic cells exhibited dense protoplasm, a high nucleoplasmic ratio, and small starch grains. Proembryos, which seemed to have a multicellular origin, formed after 16-20 wk of culture and successive cell divisions. Differentiated somatic embryos had a haustorium, a plumule, and the first and second foliar sheaths. In differentiated embryos,
\end{abstract}

\section{Z. G. Luis}

Institute of Biology, PPG-BOT, University of Brasília, Campus Universitário Darcy Ribeiro,

CEP 70910-900 Brasília, DF, Brazil

T. A. Balzon · J. E. Scherwinski-Pereira $(\square)$

Embrapa Genetic Resources and Biotechnology,

Av. W5 Norte (final),

70770-917 Brasília, DF, Brazil

e-mail: jonny.pereira@embrapa.br the radicular protrusion was not apparent because it generally does not appear until after the first true leaves emerge.

Keywords Elaeis guineensis $\cdot$ Embryogenic calli $\cdot$ Zygotic embryo $\cdot$ Micropropagation $\cdot$ Morphogenesis

\section{Introduction}

Oil palm (Elaeis guineensis Jacq.) is a perennial oil crop cultivated in humid tropical regions. The agronomic importance of oil palm is a result of its high capacity to produce oil, reaching 5-7 tons/ha under optimum conditions. With more than 8 million cultivated hectares in the world, oil palm is the second largest global source of vegetable oil after soybean (Rajesh et al. 2003; Lin et al. 2009).

In Brazil, oil palm cultivars used for commercial planting are mainly of the thin-shelled tenera genotypes and are obtained from crosses between Dura palm - the fruit of which has a thick shell surrounding the seeds - and pisifera palm - the fruit of which lacks a shell. The hybrids exhibit very high variability in oil yield, with the best plants yielding up to $20-30 \%$ more than the average. However, genetic improvement of oil palm through conventional breeding is extremely slow and costly as the breeding cycle can take up to $10 \mathrm{yr}$ (Low et al. 2008).

Since the introduction of oil palm tissue culture in the 1970s, clonal propagation has been proven to be useful not only in producing uniform planting materials but also in the development of genetic engineering programs. The coefficient of variability of yield in oil palm plantations is 20 $30 \%$ because they consist of intervarietal hybrid populations (Jones 1974); the variation is due to genetic differences that could be avoided by clonal propagation. However, oil palm has a single dominant vegetative apex and does not produce adventitious or axillary shoots. Reliable vegetative propagation of oil palm was not possible before the development of 
tissue culture systems, which enabled the production of uniform materials for planting and breeding programs (Low et al. 2008; Lin et al. 2009; Luis et al. 2010; Konan et al. 2010; Beulé et al. 2011).

Besides the potential for yield increases, clonal propagation also has the advantage that desirable secondary characteristics such as reduced palm height and superior oil quality found in selected individual palms can be uniformly expressed in clones derived from that individual (Paranjothy et al. 1989). There are several factors to consider to increase the likelihood of success of clonal propagation, including the size of the explant, ease of sterilization, developmental stage of the tissue, physiological and nutritional state of the explant, and genotype (Fiuk and Rybczynski 2008). Embryo explants are convenient because oil palm fruits are readily available, have a high degree of physiological uniformity, and can be shipped long distances (Teixeira et al. 1993; Scherwinski-Pereira et al. 2012). As a result, the use of embryos facilitates the detailed study of various factors involved in culture establishment and embryogenic induction: several treatments can be tested simultaneously, and more accurate results can be obtained. For example, in vitro culture of oil palm is difficult due to problems related to phenolic oxidation. However, studies report that the benefits of activated charcoal, which is widely used for somatic embryogenesis of oil palm, are limited. Thus, basic protocols for establishing cultures for embryogenic callus induction from zygotic embryos of oil palm could eventually be useful for the production of mature somatic tissue (Silva et al. 2012).

Somatic embryogenesis is an ideal system for the study of morphological, physiological, molecular, and biochemical events occurring during the onset and development of embryogenesis in higher plants (Quiroz-Figueroa et al. 2006). In monocots, the morphology of the embryo during development varies depending on the species (Hartmann et al. 1997). In oil palm, detailed information regarding the morphological characteristics of somatic embryos derived from zygotic embryos has been very limited; however, this information could be valuable for the identification of morphological markers associated with the different stages of embryogenesis (Kim et al. 2009).

In the present study, we describe an efficient and simplified system for somatic embryogenesis and plant production from mature zygotic embryos of a Brazilian oil palm hybrid. The anatomical changes during somatic embryogenesis are also described in detail.

\section{Material and Methods}

In this study, we divided somatic embryogenesis of oil palm from mature zygotic embryos into the following four phases: callus induction, callus proliferation and maintenance, somatic embryo maturation, and plant regeneration. The mature seeds were obtained from Embrapa Amazonia Ocidental (Station of Rio Urubu), Rio Preto da Eva, Amazonas, Brazil.

Zygotic embryos were excised from mature seeds of FACM 589, a tenera oil palm hybrid. The seeds were surface-sterilized by treatment in $70 \%$ alcohol for $3 \mathrm{~min}$, followed by $2.5 \%(w / v)$ sodium hypochlorite containing $50 \mu \mathrm{L}$ Tween-20 (Sigma, St. Louis, MO) in each $100 \mathrm{~mL}$ for $40 \mathrm{~min}$, and air-dried without rinsing. The mesocarp was then removed. The nuts were surface-sterilized in $70 \%$ alcohol for $3 \mathrm{~min}$ and in $50 \%(v / v)$ commercial bleach $(2.0-2.5 \%$ sodium hypochlorite, $w / v)$ for $20 \mathrm{~min}$ and subsequently washed in three changes of sterile distilled water. To facilitate embryo excision, nuts were immersed in sterilized water for $24 \mathrm{~h}$. The embryos were then excised under aseptic conditions with a scalpel, rehydrated in sterile water for $1-2 \mathrm{~h}$, and placed on culture medium.

Induction of embryogenic calli. The callus induction phase was performed in test tubes (25-mm diameter) containing $10 \mathrm{~mL}$ callus induction medium (CIM). CIM consisted of modified MS medium (Murashige and Skoog 1962) with $2.5 \mathrm{gL}^{-1}$ Phytagel (Sigma), with or without $2.5 \mathrm{gL}^{-1}$ activated charcoal. In this experiment, the effects of $450 \mu \mathrm{M}$ 2,4-dichlorophenoxyacetic acid (2,4-D) and picloram were also evaluated. The treatments consisted of ten explants per replicate. During all callus induction periods, the cultures were placed in the dark at $25 \pm 2^{\circ} \mathrm{C}$ and subcultured every $4 \mathrm{wk}$ on the same medium type. The frequency of granular embryogenic callus formation was determined by counting the number of mature zygotic embryos forming callus out of the total number of embryos cultured on CIM and multiplying the number by 100 . To further characterize the treatments, the length of each callus in its longest dimension and the percentage of explant surface area coverage by embryogenic granular structures were measured using Image-Pro Plus 4.5 software (Media Cybernetics 2001). Data analysis was performed using Sanest statistical data analysis software (Zonta and Machado 1984).

Callus proliferation and maintenance, somatic embryo differentiation, and plant regeneration. For callus proliferation and maintenance, the embryogenic cultures induced on CIM were transferred onto secondary modified MS medium containing either picloram or $40 \mu \mathrm{M} 2,4-\mathrm{D}$ and $10 \mu \mathrm{M} 2$ isopenteniladenine (2iP), without charcoal; for each culture, the same growth regulator was used as in the CIM. The cultures were maintained in the dark at $25^{\circ} \mathrm{C}$ for up to $12 \mathrm{wk}$. To obtain embryo differentiation and mature somatic embryos, materials from the proliferation and maintenance phase were cultivated onto modified MS medium supplemented with $12.3 \mu \mathrm{M} 2 \mathrm{iP}$ and $0.54 \mu \mathrm{M}$ naphthaleneacetic 
acid (NAA), without charcoal. For plantlet development, calli containing mainly differentiating embryos were transferred into the same modified MS medium used for differentiation, but with half-strength salt concentration, no plant growth regulators, and $2.5 \mathrm{gL}^{-1}$ activated charcoal. At this phase, 12 calli from each treatment in which auxins were combined with activated charcoal were chosen at random, and the numbers of mature somatic embryos and those regenerated into plantlets were assessed over a period of 2 yr. Germinating somatic embryos forming on the embryo clumps were isolated and transferred into fresh medium to promote their development. In vitro plantlets that were approximately $6-8 \mathrm{~cm}$ in height with at least two roots were removed from the test tubes, washed thoroughly with water, and planted in a mixture of commercial substrate (Plantmax; Eucatex, Paulínia, SP) and sand (1:1) in plastic bags and placed in the greenhouse.

All media used in this study were solidified with $2.5 \mathrm{gL}^{-1}$ Phytagel. The concentration of sucrose was $30 \mathrm{gL}^{-1}$ and the $\mathrm{pH}$ was adjusted to 5.8 with $0.1 \mathrm{~N} \mathrm{NaOH}$ or $\mathrm{HCl}$ before Phytagel was added. The media were autoclaved at $121^{\circ} \mathrm{C}$ for $15 \mathrm{~min}$. For plant regeneration, the cultures were kept at a photosynthetic photon flux of $38 \mu \mathrm{molm}^{-2} \mathrm{~s}^{-1}$ provided by cool white lamps with a $16-\mathrm{hd}^{-1}$ photoperiod.

Histological analyses. Samples were selected and fixed in $2 \%$ glutaraldehyde and $4 \%$ paraformaldehyde in $0.05 \mathrm{M}$ sodium cacodylate buffer at $\mathrm{pH} 7.2$ for at least $24 \mathrm{~h}$; they were then dehydrated in an ascending ethanol series (30$100 \%$ ) and embedded in hydroxyethyl methacrylate resin (Leica, Heidelberg, Germany). The blocks with the samples were cut in a rotating microtome in 7 - to $10-\mu \mathrm{m}$-thick transverse and longitudinal sections and fixed onto slides with a drop of water. The sections were stained with $1 \%(v /$ v) toluidine blue in phosphate-buffered saline $(0.1 \mathrm{M}$, $\mathrm{pH}$ 6.8) and submitted to Lugol's iodine test to detect starch levels, then set in histological blades with synthetic resin (Entellan; Merck, Darmstadt, Germany). The histological sections were subsequently analyzed and the images were obtained using an optical microscope connected to an image capture system (Image-Pro Plus 4.5).

\section{Results and Discussion}

Induction of embryogenic callus. After $150 \mathrm{~d}$ of cultivating zygotic embryos in CIM, there were significant differences in growth responses depending on the medium employed (Fig. 1). The frequency of embryogenic callus induction on the medium containing picloram and activated charcoal reached $97.5 \%$ of the zygotic embryos in culture, while the response was $79.4 \%$ with $2,4-\mathrm{D}$ and charcoal. Both values were significantly higher than those in the corresponding culture medium without activated charcoal (Fig. 1A). The results with 2,4-D were similar to those obtained in a study by Thuzar et al. (2011), in which $79.8 \%$ of explants formed callus with 2,4-D treatment; however, this is approximately $18 \%$ lower than the response obtained with picloram in the present study.

In the literature, there is general agreement regarding the importance of growth regulators added to media for inducing embryogenic competence: auxins and cytokinins are the two most commonly employed for the activation and regulation of cellular division and differentiation (Geldner et al. 2000; Fehér et al. 2003). Within these two categories of growth regulators, the exogenous application of auxins that are considered to be "strong," including 2,4-D, picloram, and dicamba, is well documented to induce the transition of somatic cells into embryogenic cells in many plant systems. In the case of oil palm, most successful studies of vegetatively multiplying species have used media containing 2,4-D to induce somatic embryogenesis (Besse et al. 1992; Teixeira et al. 1993; Kanchanapoom and Domyoas 1999; Thawaro and Te-chato 2009; Konan et al. 2010; Jayanthi et al. 2011; Thuzar et al. 2011). One of the reasons for the widespread use of 2,4-D is the suggestion that above a certain concentration, exogenous auxins create a double effect by acting directly as auxins while also triggering the production of endogenous indole-3-acetic acid and even by acting as a stress factor (Fehér et al. 2003). However, Scherwinski-Pereira et al. (2010) recently demonstrated that picloram induces embryogenic calli in oil palm significantly more effectively than 2,4-D. In general, over $60 \%$ of the current protocols of inducing somatic embryogenesis in monocotyledons use 2,4-D, and in the case of palm, this percentage is even higher (Karami and Saidi 2010); meanwhile, its use in studies involving oil palm is almost universal (Lin et al. 2009; Konan et al. 2010). Picloram can be used to induce and/or maintain calli or suspension cultures of both dicots and monocots; it can also induce the formation of embryogenic calli and, in some cases, can be more effective than 2,4-D (George 1993). This auxin also induces embryogenic competence in pejibaye (Bactris gasipaes; Valverde et al. 1987; Steinmacher et al. 2007) and is the most effective auxin for inducing somatic embryogenesis in arecanut palm (Areca catech $u$ L.; Karun et al. 2004).

In media containing activated charcoal, the type of auxin did not significantly affect the average size of the calli in their longest dimension (Fig. 1B) or the percentage of coverage of the explants by embryogenic granular structures (Figs. $1 C$ and $2 G, H$ ). For both measurements, significant differences between 2,4-D and picloram were only observed for the culture media without activated charcoal. Thus, these results indicate that treatment with activated charcoal allows granular embryogenic calli to grow larger than those grown on media without activated charcoal (Fig. 1B). The addition of activated charcoal to the culture medium significantly increased the percentage of coverage of the explants by 
Figure 1. Induction of somatic embryogenesis from mature zygotic embryos of oil palm. (A) Frequency of induction of embryogenic calli (percent of explants). (B) length of embryogenic calli in their longest dimension (in centimeters). (C) Coverage of the explants by embryogenic granular structures (percent of embryo surface area). Different uppercase letters represent significant differences between the presence and absence of activated charcoal $(A C)$ in the medium; different lowercase letters represent differences between auxins (within a given charcoal level) according to Tukey's test at $5 \%$.
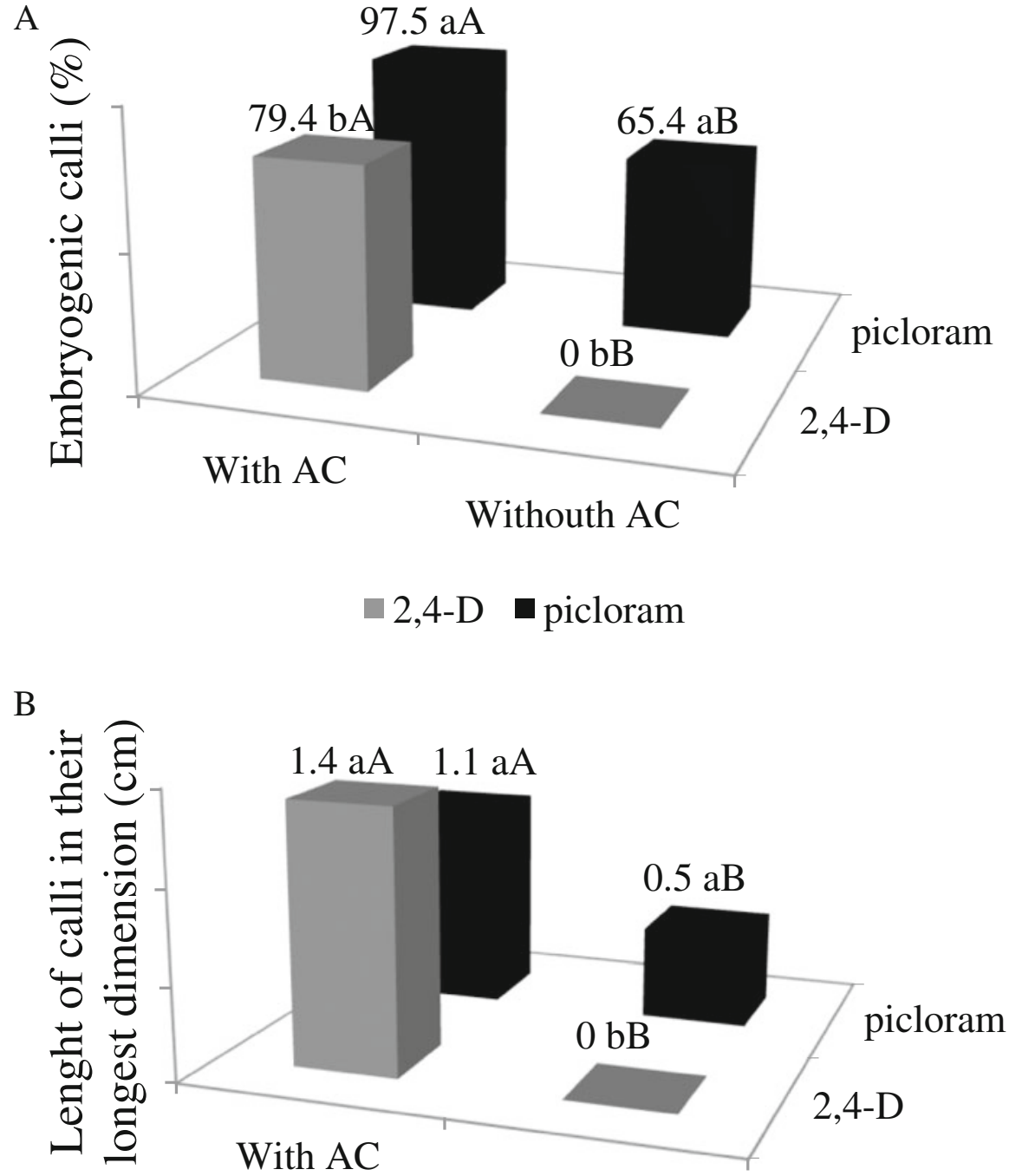

Withouth AC

$\mathrm{C}$

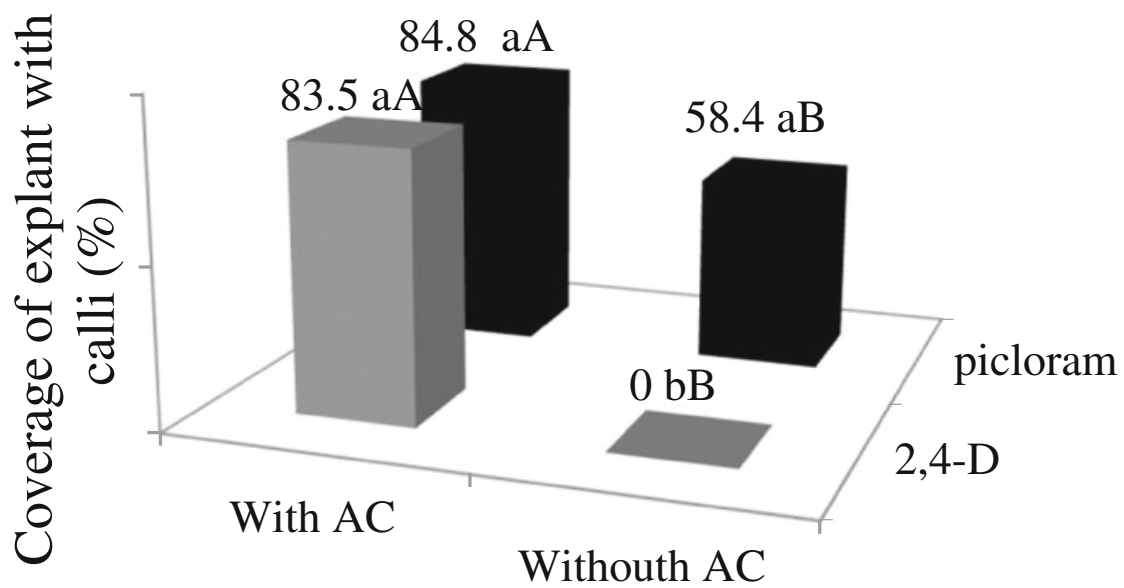

-2,4-D $\quad$ picloram 
embryogenic granular structures; in both media with activated charcoal, the percentage of the explants covered by granular structures exceeded $80 \%$ (Fig. 1C).

The use of mature and immature E. guineensis zygotic embryos as explant sources was proposed by Teixeira et al. (1993) because such embryos enable large-scale use, uniformity, ease of harvesting, long-distance transport, and resistance against fungi and bacteria, which results in decreased contamination. Furthermore, zygotic embryos are highly regenerable (Thuzar et al. 2011). In addition, in a genetic improvement program, cloning from zygotic embryos is of great importance due to its ability to accelerate culture selection cycles. This is especially true in backcross generations, in which each seed/ embryo represents a unique genotype. The ability to reproduce each genotype by cloning allows more effective evaluation through replication in field experiments.

The type of auxin added to the culture medium has a marked effect on embryogenic competence. The beneficial effect of activated charcoal may result from its ability to remove excessive and potentially inhibitory compounds from the culture medium (Thomas 2008). The adsorption of excess auxins in the culture medium by activated charcoal was also reported by Ebert and Taylor (1990) and Verdeil and Buffard-Morel (1995), who affirmed that the concentration of auxin available to the explants in cultivation in the presence of activated charcoal in the culture medium is unknown. Using immature oil palm zygotic embryos in culture medium to obtain callus proliferation, Teixeira et al. (1993) reported that the presence of $0.3 \%$ activated charcoal not only minimized oxidation but was also responsible for the adsorption of part of the 2,4-D contained in the culture medium. Consequently, the concentration of 2,4-D needed to be increased from 10 to $500 \mu \mathrm{M}$ to attain satisfactory induction of the embryogenic cultures. Regarding the types of auxins tested, "strong" auxins such as dicamba, 2,4-D, and picloram are typically used for the induction of somatic embryogenesis in agronomic species, in concentrations that usually range between 0.1 and $500 \mu \mathrm{M}$ (Akutsu and Sato 2002; Kaur and Kothari 2004; Perera et al. 2009).

Callus proliferation, somatic embryo induction, and plant regeneration. After the explants were on CIM for $150 \mathrm{~d}$ (Fig. 2A, $H$ ), embryogenic calli were transferred to a modified MS medium supplemented with $40 \mu \mathrm{M}$ picloram or 2,4-D, as in the CIM. The objective of this step was the proliferation and maintenance of the calli obtained in the previous phase. The reduction of the auxin level from 450 to $40 \mu \mathrm{M}$ was crucial for establishing repetitive cycles of cellular division and for repressing the differentiation processes, ultimately enabling the calli to multiply (Fig. $2 I, J$ ). In this phase, it was possible to observe the proliferation of embryogenic calli with nodular aspects that were compact and light yellow, which is characteristic of type II callus.
However, after $12 \mathrm{wk}$ in this culture medium, small regions developing friable white calli that were weakly connected to the rest of the embryogenic nodular calli also appeared (Fig. 2J). After $12 \mathrm{wk}$, the embryogenic calli were transferred to modified MS medium supplemented with $0.54 \mu \mathrm{M}$ $\mathrm{NAA}$ and $12.3 \mu \mathrm{M} 2 \mathrm{iP}$ for the differentiation and maturation phases. The passing of the embryogenic calli to this stage made it possible to observe somatic embryo differentiation and maturation (Fig. $2 K$ ). Once the embryos matured, they were transferred to a new culture medium free of growth regulators, but with $2.5 \mathrm{gL}^{-1}$ activated charcoal to stimulate the germination of the differentiated somatic embryos into plants, as evidenced by the emergence of the foliar sheath (Fig. 2L).

In this study, individual plants regenerated from the somatic embryo clumps were separated and transferred to fresh medium without growth regulators to complete development (Fig. 2M). Isolation of germinated somatic embryos after differentiation was important because it allowed continuous proliferation and differentiation of plants from the clusters of somatic embryos, suggesting that this could be applied for the large-scale cultivation of plants of this species (Konan et al. 2010). Here, individual somatic embryos formed extensive roots after $8-24 \mathrm{wk}$ in medium without growth regulators - the period required for the plants to attain sufficient growth for acclimatization (Fig. $2 N$ ).

The effects of cytokinins on the somatic embryogenesis of palm are not yet completely understood. Guerra and Handro (1998) stated that using cytokinins in the callus induction medium improved somatic embryogenesis induction rates in Euterpe edulis. However, Steinmacher et al. (2007) did not observe any improvement in the efficiency of somatic embryogenesis induction in pejibaye when $2 \mathrm{iP}$ was added to the induction medium. According to another report, the increase in cytokinin concentrations in certain stages of palm tree embryogenesis may accelerate the oxidation and darkening of tissues (Sarasan et al. 2002). Aberlenc-Bertossi et al. (1999) reported that the addition of BAP increases the germination rates of somatic embryos of oil palm. Scherwinski-Pereira et al. (2010) showed that the use of cytokinins in more advanced phases is important for the complete differentiation of somatic embryos, whereas its use is also recommended in the differentiation and maturation phases of the somatic embryos of this species. However, the use of cytokinins in the different stages of somatic embryogenesis in oil palm appears to be of limited use - especially during regeneration - because this growth regulator may be associated with problems of abnormal flowering in this species (i.e., mantled flowers), thus requiring extensive monitoring of the regenerated plants under field conditions (Jones et al. 1995; Aberlenc-Bertossi et al. 1999). This problem has not been reported for other palm tree species. 

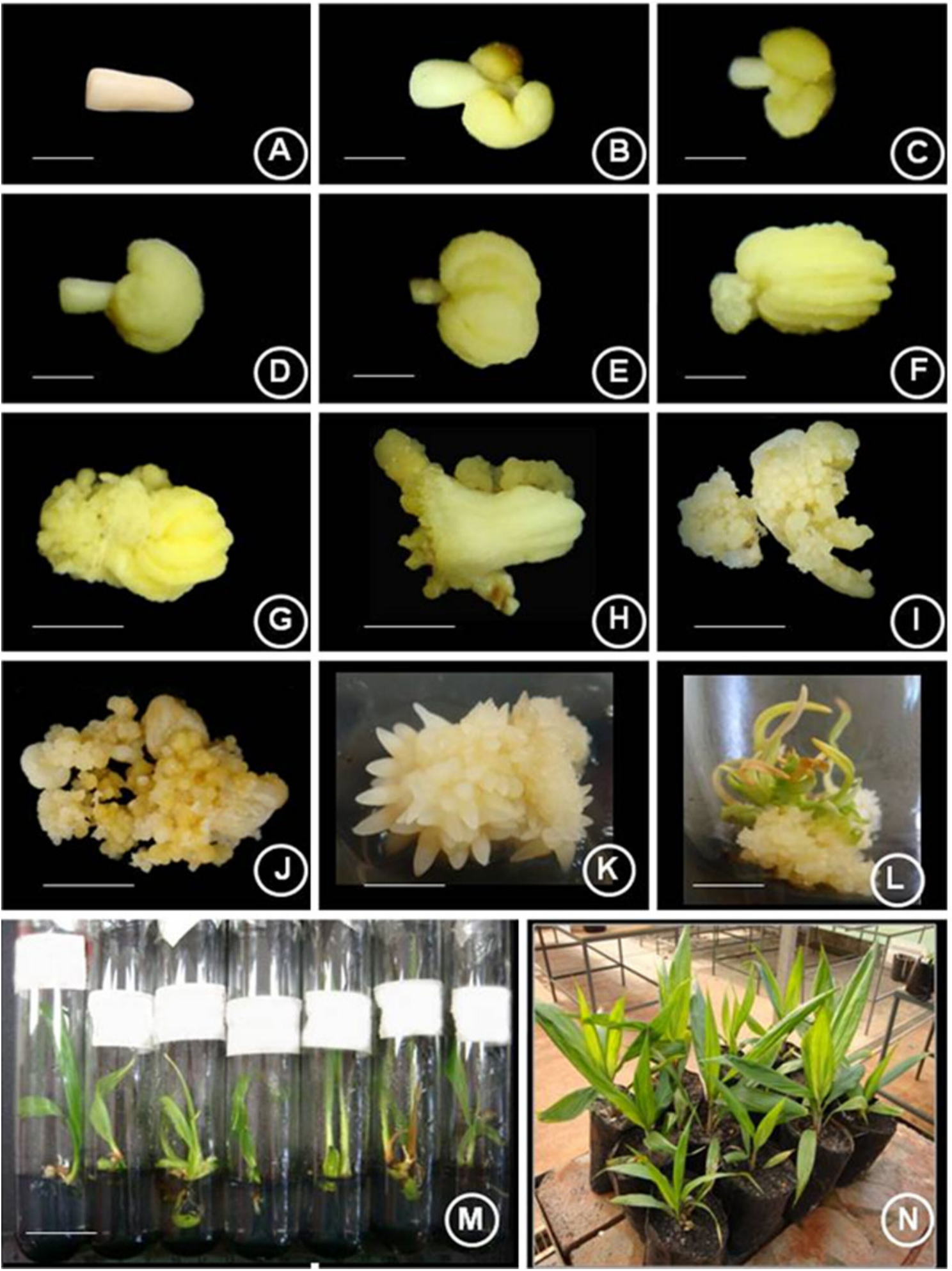

Figure 2. Morphological stages of somatic embryos in oil palm from mature zygotic embryos. (A) Zygotic embryo of oil palm used as explant source. $(B-F)$ Beginning of the development of the primary callus in the distal region of the explants. $(G, H)$ Primary calli with embryonic multi-

Most of the embryogenic calli in this study were capable of producing somatic embryos in a repetitive and non- granular structures starting to cover the explant on induction medium with picloram. $(I-J)$ Calli on multiplication medium. $(K)$ Somatic embryos. $(L)$ Regeneration of plants. $(M)$ Regenerated plants. $(N)$ Acclimatized plantlets. Bars, $0.3 \mathrm{~cm}(A-F) ; 0.5 \mathrm{~cm}(G-K) ; 2.0 \mathrm{~cm}(L, M)$.

synchronous fashion (Fig. 2K). These embryos continuously produced somatic embryos for mo or $\mathrm{yr}$, as described by 
Figure 3. Effects of picloram and 2,4-D combined with activated charcoal on plantlet regeneration. $(A)$ Number of somatic embryos. $(B)$ Number of plantlets regenerated per callus. (C) Regeneration frequency after up to $2 \mathrm{yr}$ on the regeneration medium. The regeneration frequency was calculated as the ratio of total regenerants/number of somatic embryos $\times 100$. Data were the mean from 12 explants (embryogenic calli) per treatment. Different letters indicate significant differences according to $F$ tests at $5 \%$.

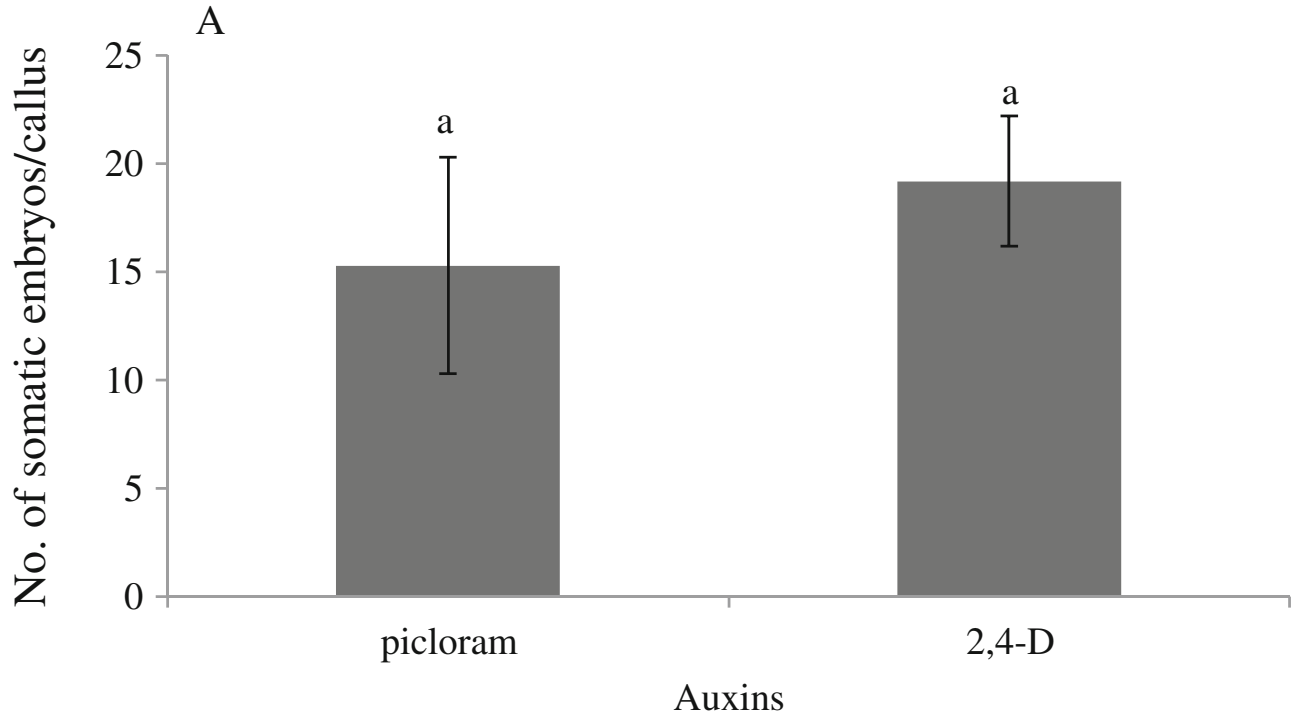

B

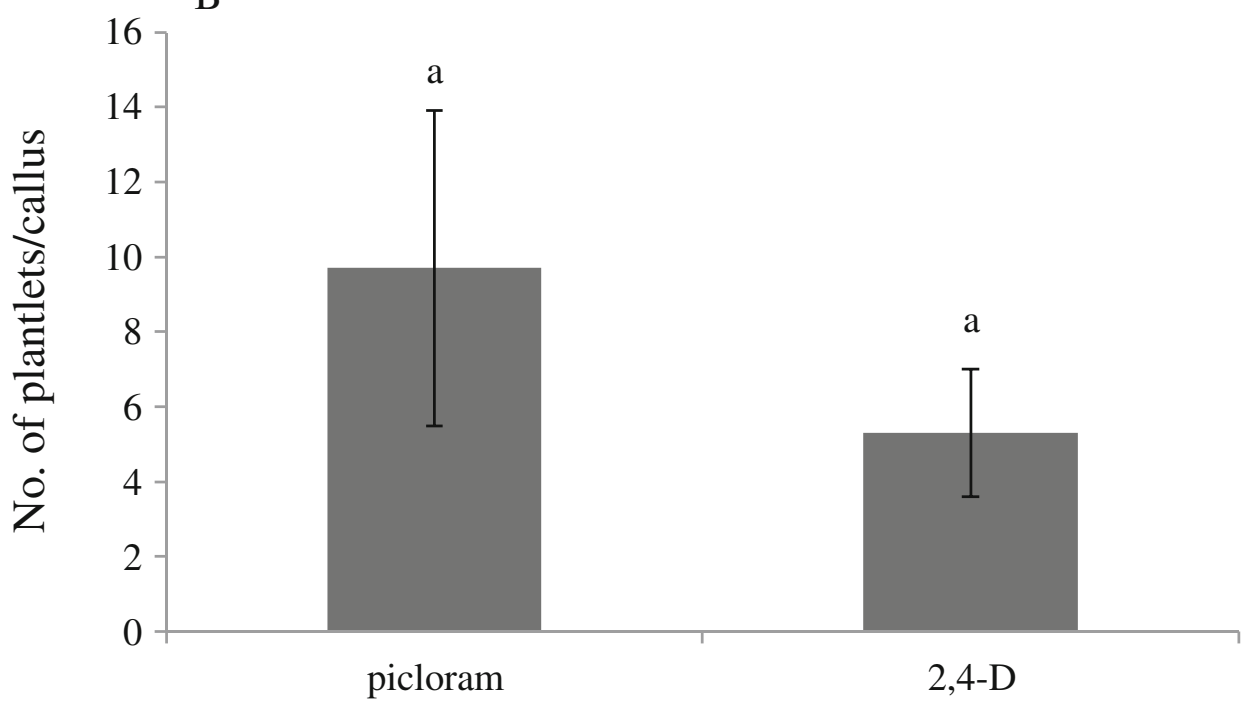

Auxins

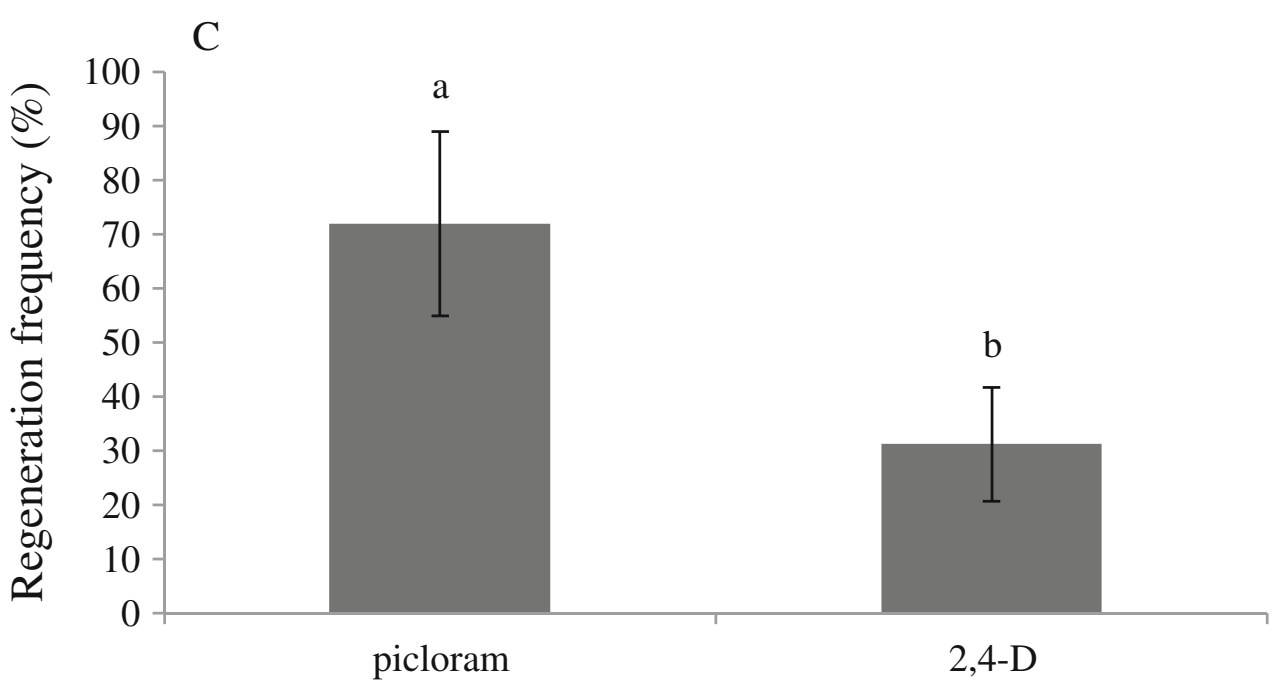

Auxins 
Konan et al. (2010). In the present study, the calli induced on the medium containing picloram had higher regeneration frequencies than those induced on the medium with 2,4-D (Fig. 3). Similar results were reported by Te-Chato and Hilae (2007) and Thuzar et al. (2011) who reported regeneration frequencies of $56 \%$ and $78 \%$, respectively. Plantlet regeneration depends on the clonal origin of the embryo line and age of the culture (Konan et al. 2010). Certain embryogenic lines maintained their regeneration potential over $20 \mathrm{yr}$; this indicates that the proliferating lines maintained their multiplication and plant regeneration potential intact since regeneration frequencies exceeding $50 \%$ were observed after 7 yr (Konan et al. 2010).

Histological analyses of oil palm embryogenic calli. Histological analysis indicated that regions with intense cellular divisions were observed in the most internal part of the calli. Proliferative embryogenic tissue contained isodiametric small cells with dense cytoplasm and a voluminous nucleus (Fig. 4A). Starting from the development of the embryogenic mass, it was possible to observe the formation of proembryos (Fig. 4C); furthermore, we observed embryos that seemed to be of multicellular origin (Fig. 4D). Embryos of multicellular origin appear joined to their tissue of origin, have a common protoderm, and originate from nodular calli comprising embryogenic masses, leading to the formation of globular embryos (Williams and Maheswaran 1986). Saénz et al. (2006) also observed that somatic embryos of Cocos nucifera exhibit multicellular origin and were formed from nodular calli. Embryos in the more advanced globular stages (Fig. 4E) in which cells had a prominent nucleus containing one to three nucleoli were also observed. These embryos appeared individualized by apparent wall thickening. This type of wall thickening around the embryos was also observed by Sané et al. (2006) in somatic embryogenesis induction in calli of Phoenix dactylifera.

In the external region of the callus and close to the sites with intense cellular divisions, large cells containing starch, as evidenced by brown coloration provided by Lugol's iodine solution, were verified (Fig. 4B). The starch grains accumulated mainly in the cells close to the centers of intense cellular division, especially in those with less dense cytoplasm; meanwhile, in the cells with intense division, the proembryos did not have starch grains.

The accumulation of starch either in the embryogenic cells or in adjacent cells of the explant appears to be a phenomenon related to the acquisition of embryogenic competence. Kanchanapoom and Domyoas (1999) also detected the accumulation of starch in the calli and bipolar embryoids of E. guineensis, indicating that starch accumulation accompanies the formation of somatic embryos. In addition, the starch in embryogenic cells of Gentiana punctata calli represents an energy source for intense cellular division and the
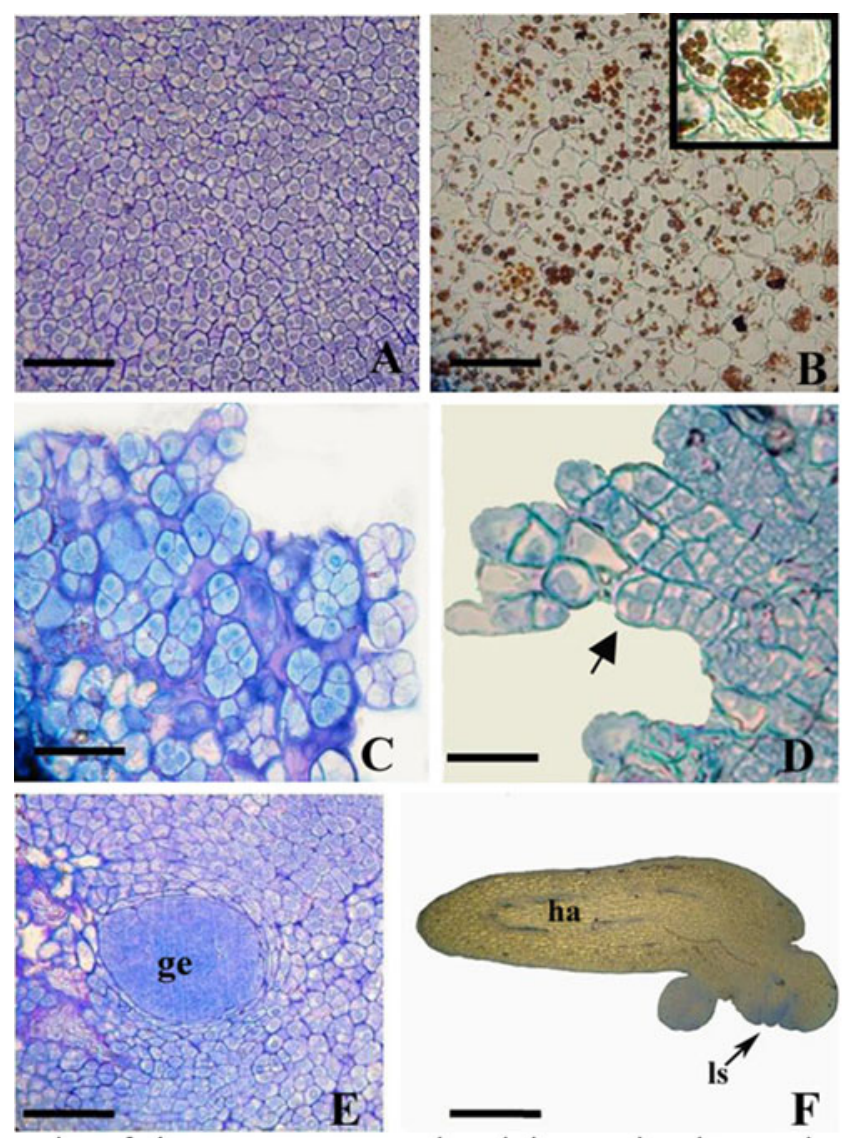

Figure 4. Sections of E. guineensis Jacq. explants during somatic embryogenesis. (A) Region with meristematic cells characterized by voluminous nucleus and dense cytoplasm and with intense cellular division. $(B)$ Cells containing starch grains, provided by Lugol's iodine solution, located near regions of intense cellular division. (C) Start of formation of proembryos. $(D)$ Explant with formations of embryos in a stage similar to the globular stage (arrow). (E) Globular embryo (ge) surrounded by meristematic cells. $(F)$ Somatic embryo with haustorium (ha) and apical apex of the stem with two foliar sheaths (ls). Bars, $50 \mu \mathrm{m}(A, D) ; 100 \mu \mathrm{m}(B, C) ; 10 \mu \mathrm{m}(E, F)$.

subsequent development of the embryos (Mikula et al. 2004). According to Silveira et al. (2004), the level of starch may change depending on the embryo growth phase because cellular division and differentiation demand large quantities of carbon and ATP. Finally, completely regenerated somatic embryos with a haustorium, plumule, and the start of the development of the first and second foliar sheaths were observed (Fig. $4 F$ ). In this phase, it was not possible to visualize the root bud, as was also reported by Camillo et al. (2009), because radicular protrusion only occurs after the first true leaves emerge.

In conclusion, a protocol for obtaining a high frequency of embryogenic calli from zygotic embryos of oil palm was developed. In addition, the auxin picloram and the use of activated charcoal significantly improved embryogenic callus induction. The protocol described here will be useful for future studies on oil palm because the detailed description of 
the morphological routes involved in the different stages of the process can serve as a guide for other researchers working toward the goal of more easily cloning this species from mature zygotic embryos.

Acknowledgments This work was supported by Conselho Nacional de Desenvolvimento Científico e Tecnológico- $\mathrm{CNPq}$, Brazil. We thank Dr. Ricardo Lopes and Dr. Raimundo Nonato (Brazilian Oil Palm Breeding Program), Embrapa Amazonia Ocidental, Brazil, for providing the biological material for experiments. We also wish to extend our thanks to Rafael C. Silva for his contributions.

\section{References}

Aberlenc-Bertossi F, Noirot M, Duval Y (1999) BA enhances the germination of oil palm somatic embryos derived from embryogenic suspension cultures. Plant Cell Tiss Org Cult 56:53-57

Akutsu M, Sato H (2002) Induction of proembryos in liquid culture increases the efficiency of plant regeneration from Alstroemeria calli. Plant Sci 163:475-479

Besse I, Verdei JL, Duval Y, Sotta B, Maldiney R, Miginiac E (1992) Oil palm (Elaeis guineensis Jacq.) clonal fidelity: endogenous cytokinins and indoleacetic acid in embryogenic callus cultures. J Exp Bot 252:983-989

Beulé T, Camps C, Debiesse S, Tranchant C, Dussert S, Sabau X, Jaligot E, Alwee SSRS, Tregear JW (2011) Transcriptome analysis reveals differentially expressed genes associated with the mantled homeotic flowering abnormality in oil palm (Elaeis guineensis). Tree Genet Genomes 7:169-182

Camillo J, Luis ZG, Scherwiski-Pereira JE (2009) Tolerância de sementes de dendezeiro à criopreservação. Pesq Agrop Bras 44:211-215

Ebert A, Taylor HF (1990) Assessment of the changes of 2,4-dichlorophenoxyacetic acid concentrations in plant tissue culture media in presence of activated charcoal. Plant Cell Tissue Org Cult $20: 165-172$

Fehér A, Pasternak TP, Dudits D (2003) Transition of somatic plant cells to an embryogenic state. Plant Cell Tiss Org Cult 74:201228

Fiuk A, Rybczynski JJ (2008) Genotype and plant growth regulatordependent response of somatic embryogenesis from Gentiana spp. leaf explants. In Vitro Cell Dev Biol—Plant 44:90-99

Geldner N, Hamann T, Jurgens G (2000) Is there a role for auxin in early embryogenesis? Plant Growth Regul 32:187-191

George EF (1993) Plant propagation by tissue culture - the technology. Exegetics, Edington, UK

Guerra MP, Handro W (1998) Somatic embryogenesis and plant regeneration in embryo cultures of Euterpe edulis Mart (Palmae). Plant Cell Rep 7:550-552

Hartmann HT, Kester DE, Davies JFT, Geneve RL (1997) Plant propagation, principles and practices, 6th edn. Prentice Hall, Englewood Cliffs

Jayanthi M, Mohan NM, Mandal PK (2011) Direct somatic embryogenesis and plantlet regeneration in oil palm. J Plant Biochem Biotechnol 20:249-251

Jones LH (1974) Propagation of clonal palms by tissue culture. Oil Palm News 17:1-8

Jones LH, Hanke DE, Eewens CJ (1995) An evaluation of the role of cytokinins in the development of abnormal inflorescences in oil palm (Elaeis guineensis Jacq) regenerated from tissue culture. Plant Growth Regul 14:135-142
Kanchanapoom K, Domyoas P (1999) The origin and development of embryoids in oil palm (Elaeis guineensis Jacq) embryo culture. Sci Asia 25:195-202

Karami O, Saidi A (2010) The molecular basis for stress-induced acquisition of somatic embryogenesis. Mol Biol Rep 37:24932507. doi:101007/s11033-009-9764-3

Karun A, Siril EA, Radha A, Parthasarathy VA (2004) Somatic embryogenesis and plantlet regeneration from leaf and inflorescence explants of arecanut (Areca catechu L.). Curr Sci 86:1623-1628

Kaur P, Kothari SL (2004) In vitro culture of kodo millet: influence of 2,4-D and picloram in combination with kinetin on callus initiation and regeneration. Plant Cell Tiss Org Cult 77:73-79

Kim TD, Ahn CH, Bae KH, Choi YE (2009) The embryogenic competency and morphological changes during somatic embryogenesis in Iris pseudacorus. Plant Biotechnol Rep 3:251-257

Konan KE, Durant-Gasselin T, Kouadio YJ, Flori A, Rival A, Duval Y, Pannetier C (2010) In vitro conservation of oil palm somatic embryo for $20 \mathrm{yr}$ on a hormone-free culture medium: characteristics of the embryogenic cultures, derived plantlets and adult palms. Plant Cell Rep 29:1-13

Lin HC, Morcillo F, Dussert S, Tranchant-Dubreuil C, Tregear JW, Tranbarger TJ (2009) Transcriptome analysis during somatic embryogenesis of the tropical monocot Elaeis guineensis: evidence for conserved gene functions in early development. Plant Mol Biol 70:173-192

Low E, Alias H, Boon S, Shariff EM, Tan CA, Ooi LC, Cheah S, Raha A, Wan K, Singh R (2008) Oil palm (Elaeis guineensis Jacq) tissue culture ESTs: identifying genes associated with callogenesis and embryogenesis. BMC Plant Biol 8:62

Luis ZG, Bezerra KMB, Scherwinski-Pereira JE (2010) Adaptability and leaf anatomical features in oil palm seedlings produced by embryo rescue and pre-germinated seeds. Braz J Plant Physiol 22:209-215

Media Cybernetics (2001) Image Pro Plus: images database user guide for Windows, version 4.5. Media Cybernetics, Silver Spring

Mikula A, Tykarska T, Zielinska M, Kuras M, Rybczynski JJ (2004) Ultrastructural changes in zygotic embryos of Gentiana punctata L. during callus formation and somatic embryogenesis. Acta Biol Cracov 46:109-120

Murashige T, Skoog F (1962) A revised medium for rapid growth and bio-assays with tobacco tissue cultures. Physiol Plant 15:473-497

Paranjothy K, Rohani O, Tarmizi AH, Tan CS, Tan CC (1989) Current status and strategies of oil palm tissue culture research. 1989 PORIM International Palm Oil Development Conference, pp 109-121

Perera PIP, Vidhanaarachchi VRM, Gunathilake TR, Yakandawala DMD, Hocher V, Verdeil JL, Weerakoon LK (2009) Effect of plant growth regulators on ovary culture of coconut (Cocos nucifera L.). Plant Cell Tiss Org Cult 99:73-81

Quiroz-Figueroa FR, Rojas-Herrera R, Galaz-Avalos RM, LoyolaVargas VM (2006) Embryo production through somatic embryogenesis can be used to study cell differentiation in plants. Plant Cell Tiss Org Cult 86:285-301

Rajesh MK, Radha E, Karun A, Parthasarathy VA (2003) Plant regeneration from embryo-derived callus of oil palm - the effect of exogenous polyamines. Plant Cell Tiss Org Cult 75:41-47

Saénz L, Azpeitia A, Chuc-Armendariz B, Chand JL, Verdeil JL, Hocher V, Oropeza C (2006) Morphological and histological changes during somatic embryo formation from coconut plumule explants. In Vitro Cell Dev Biol—Plant 42:19-25

Sané D, Aberlenc-Bertossi F, Gassama-Dia YK, Sagna M, Trouslot MF, Duval Y, Borgel A (2006) Histocytological analysis of callogenesis and somatic embryogenesis from cell suspensions of date palm (Phoenix dactylifera). Ann Bot 98:301-308

Sarasan V, Ramsay MM, Roberts AV (2002) In vitro germination and induction of direct somatic embryogenesis in 'bottle palm' 
[Hyophorbe lagenicaulis (L. Bailey) H.E. Moore], a critically endangered Mauritian palm. Plant Cell Rep 20:1107-1111

Scherwinski-Pereira JE, Guedes RS, Fermino PCP Jr, Silva TL, Costa FHS (2010) Somatic embryogenesis and plant regeneration in oil palm using the thin cell layer technique. In Vitro Cell Dev BiolPlant 46:378-375

Scherwinski-Pereira JE, Guedes RS, Silva RA, Fermino PCP Jr, Luis ZG, Freitas EO (2012) Somatic embryogenesis and plant regeneration in açaí palm (Euterpe oleracea). Plant Cell Tiss Org Cult 109:501-508

Silva RC, Luis ZG, Scherwinski-Pereira JE (2012) Differential responses to somatic embryogenesis of different genotypes of Brazilian oil palm (Elaeis guineensis Jacq.). Plant Cell Tiss Org Cult 111:59-67. doi:10.1007/s11240-012-0170-5

Silveira V, Floh EIS, Handro W, Guerra MP (2004) Effect of plant growth regulators on the cellular growth and levels of intracellular protein, starch and polyamines in embryogenic suspension cultures of Pinus taeda. Plant Cell Tiss Org Cult 76:53-60

Steinmacher DA, Cangahuala-Inocente GC, Clement CR, Guerra MP (2007) Somatic embryogenesis from peach palm zygotic embryos. In Vitro Cell Dev Biol-Plant 43:124-132

Te-chato S, Hilae A (2007) High-frequency plant regeneration through secondary somatic embryogenesis in oil palm (Elaeis guineensis Jacq. var. tenera). J Agric Technol 3:345-357
Teixeira JB, Sondahll MR, Kirb EG (1993) Somatic embryogenesis from immature zygotic embryos of oil palm. Plant Cell Tiss Org Cult 34:227-233

Thawaro S, Te-chato S (2009) Effect of genotypes and auxins on callus formation from mature zygotic embryos of hybrid oil palms. J Agric Technol 5:167-177

Thomas TD (2008) The role of activated charcoal in plant tissue culture. Biotechnol Advances 26:618-631

Thuzar M, Vanavichit A, Tragoonrung S, Jantasuriyarat C (2011) Efficient and rapid plant regeneration of oil palm zygotic embryos cv. 'Tenera' through somatic embryogenesis. Acta Physiol Plant 33:123-128

Valverde R, Arias O, Thorpe TA (1987) Picloram-induced somatic embryogenesis in pejibaye palm (Bactris gasipaes H.B.K.). Plant Cell Tiss Org Cult 10:149-156

Verdeil JL, Buffard-Morel J (1995) Somatic embryogenesis in coconut (Cocos nucifera L.). In: Bajaj YPS (ed) Somatic embryogenesis and synthetic seed. Biotechnology in agriculture and forestry, vol. 30. Springer, Berlin, pp 299-317

Williams EG, Maheswaran G (1986) Somatic embryogenesis: factors influencing coordinated behaviour of cells as an embryogenic group. Ann Bot 57:443-462

Zonta EP, Machado AA (1984) SANEST—Sistema de Análise Estatística para Microcomputadores Registrado na Secretaria Especial de Informática sob n 066060 - categoria A. Universidade Federal de Pelotas, Pelotas, RS, Brazil 